\title{
贵州正安旦坪向斜铝土矿成矿规律与过程探究
}

杨仕江

贵州省有色金属和核工业地质勘查局三总队

DOI:10.32629/gmsm.v2i5.307

[摘 要] 通过贵州正安旦坪向斜内新木一晏溪铝土矿矿区、中观铝土矿矿区勘查资料数据处理,在分析成矿环境、特征的基础 上,研究该区铝土矿成矿规律特征,进一步总结成矿环境和成矿过程。

[关键词] 正安; 旦坪向斜; 铝土矿; 成矿规律; 风化; 搬运; 分异; 淋滤; 沉积

旦坪向斜内目前已发现多个大中型铝土矿床, 新木-晏 溪、红光坝等矿区已达到详查工作程度, 整个构造内估算的资 源量大于 5000 万吨, 由此可见, 该向斜构造内铝土矿资源禀赋, 该区域是铝土矿有利成矿环境。从本队在该构造区内探矿情 况看, 其构造内不同部位铝土矿富集情况又存在很大差异。

本文的撰写, 数据来源主要为本队勘查的新木一晏溪铝 土矿矿区、中观铝土矿矿区勘查资料, 其次参考了黔北地区 铝土矿文献, 在此一并感谢。

\section{1 成矿环境}

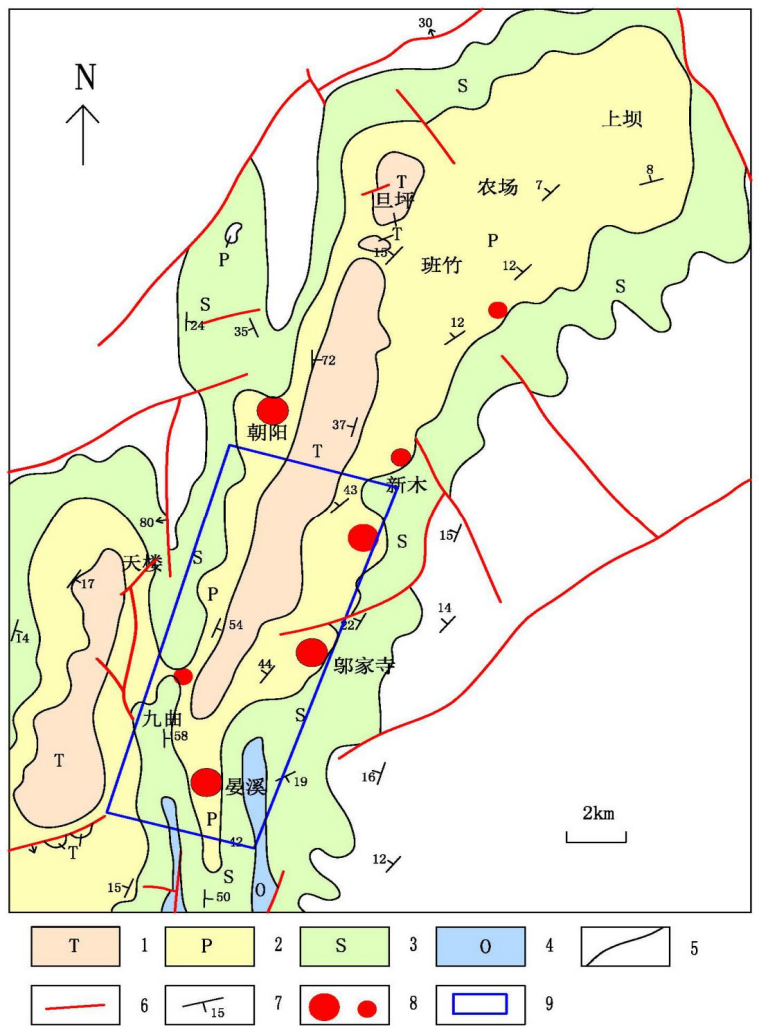

图1 研究区成矿环境图

1-三叠系 2-二叠系 3-志留系 4-奥陶系 5-地层界线 6-断层 7-产状 8-铝土矿床 9-研究区范围

1. 1 区域成矿环境

本区域位于扬子准地台黔北台隆遵义断拱风冈北北东
向构造变形区内。构造轴线以北东、北北东方向为主, 向斜 较狭窄, 向斜总体东翼倾角较缓, 一般为 $20^{\circ} \sim 40^{\circ}$, 西翼较 陡, 一般为 $60^{\circ} \sim 80^{\circ}$ 。断裂多沿背斜轴部及两翼 $\in-\mathrm{S}$ 等老 地层中分布, 长数公里至数十公里, 规模宏大, 以冲断层为 主。区域内除缺失泥盆系以外, 自寒武系至侏罗系均有分布。 主要矿产有铝土矿、铁、煤、黄铁矿、耐火粘土、含钾页岩、 重晶石、萤石、采、铅锌、石灰石等。

\section{2研究区成矿环境}

研究区位于旦坪向斜中南段 (图1)。旦坪向斜轴向由南部的 南北向往北渐转为北北东向, 局部略有扭曲。向斜长 40 余公里, 宽6 14公里。由向斜翼部向核部, 其地层依次为韩家店群、梁 山组、栖霞组与茅口组、吴家坪组、长兴组、夜郎组, 轴部出露 地层为三叠系茅草铺组。该向斜不对称: 东翼岩层倾向 $290^{\circ} \sim$ $340^{\circ}$, 倾角 $8 \sim 45^{\circ}$; 西翼岩层倾向 $90^{\circ} \sim 150^{\circ}$, 倾角较陡, 一 般 $40^{\circ} \sim 60^{\circ}$, 局部可达 $70^{\circ}$ 以上。研究区断裂构造以北东走向 及近东西走向为主, 大部分为正断层, 显张性为主, 规模最大的 断层长 3300 米以上。大部分断层分布在矿体边缘或远离矿体。

\section{2 成矿特征}

\section{1 矿床类型}

研究区内矿床工业类型属 “产于碳酸盐侵蚀面上的、沉 积型的一水硬铝石铝土矿矿床”。矿床含矿层直接底板为志 留系韩家店群的页岩或砂质页岩, 有少量为上石炭统黄龙组 的结晶灰岩, 该层已被剥蚀得面目全非, 原厚不明。

2. 2 矿体特征

研究区铝土矿矿层赋存于二叠系梁山组 (P21) 中上部 (图2)。含矿岩系常含细粒状黄铁矿, 同时局部含硫较高。

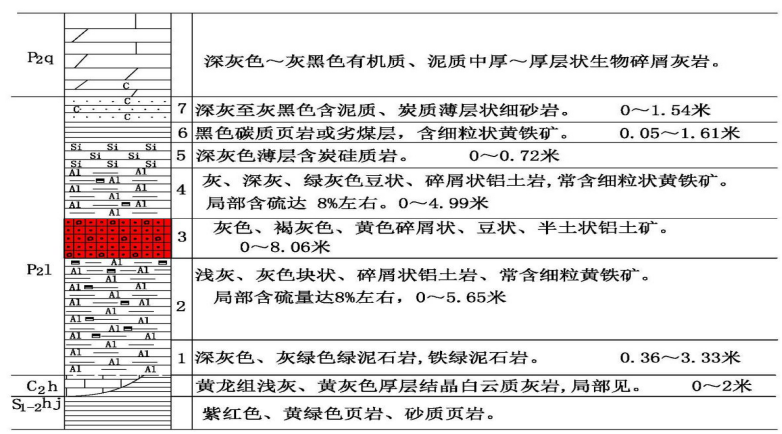

图2 含矿岩系柱状图 
向斜南东翼矿体呈层状产出 (图3), 产状与围岩一致。倾 向西至北西西, 倾角 $10 \sim 50^{\circ}$ 。矿体边缘较平整, 仅局部略呈 港湾状, 内部无天窗, 矿层无分支、复合现象, 矿层内极少见夹 层。矿体内部结构简单。矿体在地表若厚度及质量变化大时, 其往深部延伸一般不远且矿体规模小。该翼铝土矿石主要化 学组分的平均值为: Al203 55. 83\%; Si0211. 66\%; Fe20311. 78\%; Ti023. 20\%; 烧失量 $14.92 \%$; S1.79\%, 铝硅比4.8。

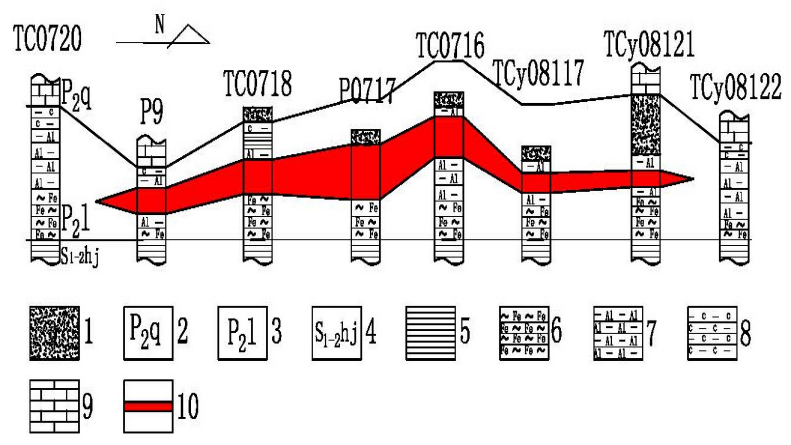

图3 旦坪向斜东翼露头线对比图

1-第四系 2-中二叠统栖霞组 3-中二叠统梁山组 4中、下志留统韩家店组 5-页岩 6-绿泥石岩 7-铝土岩 8炭质泥岩 9-灰岩 10-铝土矿

向斜北西翼矿体呈似层状、透镜状, 产状与地层基本一 致。地表露头一般能达到工业开采, 但是深部 10 个钻孔仅 2 个达到工业指标。本队在西翼对设立的中观铝土矿开展普查 工作, 仅圈定了一个矿体, 获得 (333) 资源量 30 万吨, 远不能 和东部两三千万吨级资源量规模矿床相提并论。该翼矿石中 A120346. 72 71. 25\%, 平均 $55.12 \%$; Si022. $71 \sim 25.55 \%$, 平均 10. $60 \%$; $\mathrm{Fe} 2036.5 \sim 19.36 \%$, 平均9. 56\%; Ti02. 49 3. $95 \%$, 平均 $2.44 \%$; TS0. $06 \sim 6.99 \%$, 平均 $1.34 \%$; 烧失量 12.40 16. $23 \%$, 平均 $13.75 \% ; \mathrm{A} / \mathrm{S} 1.8 \sim 24.1$, 平均 5.2 。

\section{3 矿石特征}

矿石中有用矿物主要为一水硬铝石 (表1), 占矿物总量 $27.91 \sim 92.71 \%$ 。其次为粘土矿物, 包括高岭石 (微量至 48. 25\%)、伊利石 (微量至3. 44\%)、蒙托石 (微量至7\%)、绿泥 石 (微量至 7. 17\%), 勃姆石 (微量)、叶蜡石 (微量至5. 74\%), 角闪石 (微量至 $2.87 \%$ ) ; 再次为铁矿物、石英、方解石、石 膏等, 约占矿总量 $1 \sim 3 \%$; 局部矿层底部矿石中黄铁矿较多。 重矿物主要为锐铁矿。重矿物约占 $1 \%$ 左右。灰白色半土状铝 土矿中含一水硬铝石高, 可达 $90 \%$ 以上, 碎屑状铝土矿中含一 水硬铝石一般在 50-60\%, 豆状铝土矿中含一水硬铝石较低, 一般在 $30-40 \%$ 。

表1 矿石矿物成分表

\begin{tabular}{|c|c|c|c|c|c|c|}
\hline 矿物 & 铅矿物 & 粘土矿物 & 铁矿物 & 重矿物 & $\begin{array}{c}\text { 碳酸盐 } \\
\text { 矿物 }\end{array}$ & $\begin{array}{c}\text { 其他 } \\
\text { 矿物 }\end{array}$ \\
\hline 主要的 & $\begin{array}{c}\text { 一水硬铝 } \\
\text { 石 }\end{array}$ & $\begin{array}{c}\text { 高岭石、蒙脱石、 } \\
\text { 伊利石、绿泥石 }\end{array}$ & $\begin{array}{c}\text { 黄铁矿、纤铁矿、赤、铁矿 } \\
\text { 次要的 }\end{array}$ & 锐铁 & & \\
勃姆石、叶蜡石 & 铁绿泥石角闪石 & & 方解石 & $\begin{array}{c}\text { 石英、 } \\
\text { 石膏 }\end{array}$ \\
\hline
\end{tabular}

\section{3 成矿规律}

3. 1 矿体分布及厚度变化规律

利用勘查数据分析处理后, 可以看出含矿岩系底板地貌 总体和旦坪向斜形态一致, 局部存在多个负地形地貌 (图4)。 矿体集中分布在旦坪向斜南东翼及褶皱转折和末端。负地貌 地区矿体相对较厚, 褶皱转折和末端相对较厚。向斜东翼矿 体总体较西翼厚, 浅部较深部厚 (图5)。

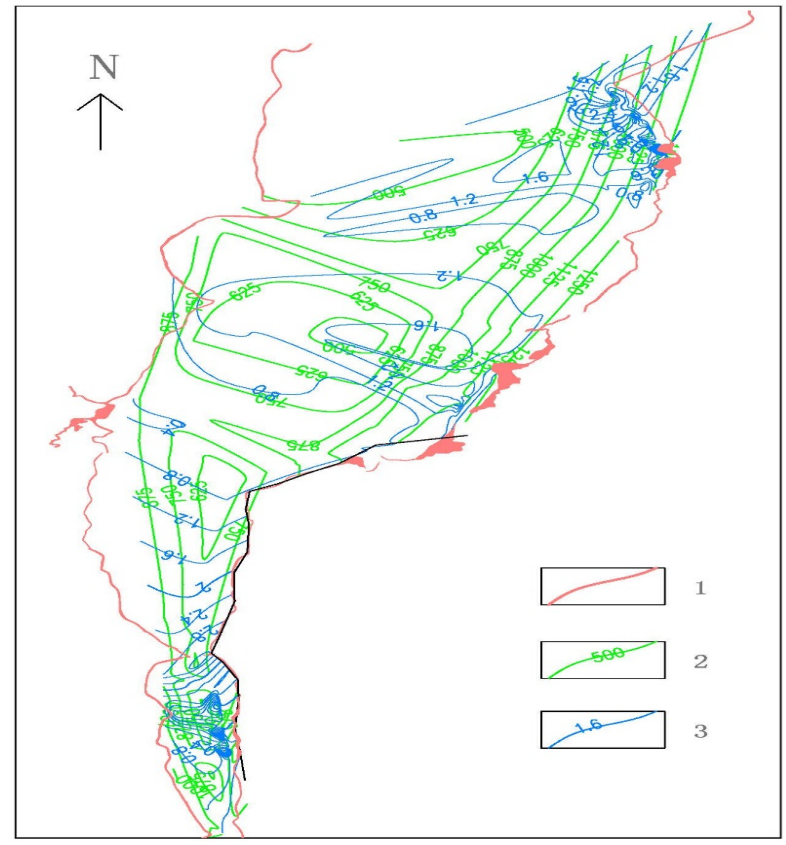

图4 含矿岩系底板等高线与矿体等厚线叠加图 1-含矿岩系露头 2-含矿岩系底板等高线 3-矿体等厚线

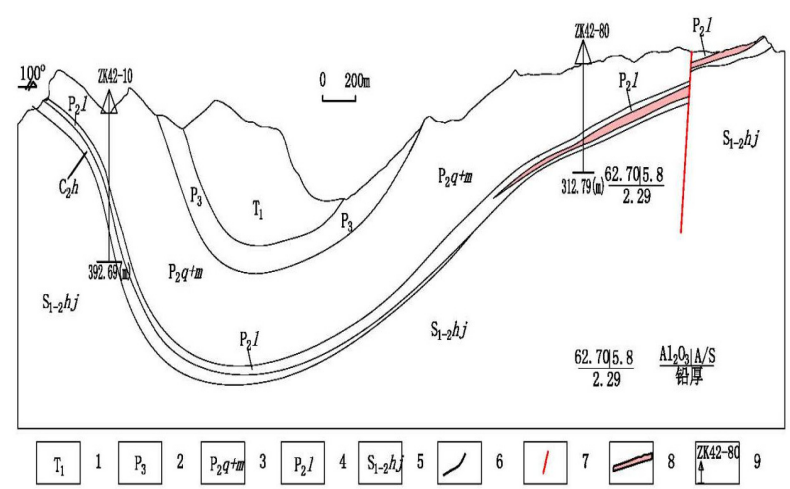

图5 向斜两翼成矿对比剖面图

1-下三叠统 2-上三叠统 3-中二叠统栖霞、茅口组 4中二叠统梁山组 5-志留系韩家店群 6-地层界线 7-断层 8-矿体 9-钻孔及编号

3. 2 矿体厚度与下伏黄龙组灰岩厚度变化规律

通过矿体厚度与黄龙灰岩厚度的160个散点分布图可以 看出, 黄龙灰岩厚度越小, 达到工业厚度的分析点越多 (图 6)。由此可以得出, 矿体主要集中在黄龙组灰岩沉积薄或被 剥蚀严重的地段。 


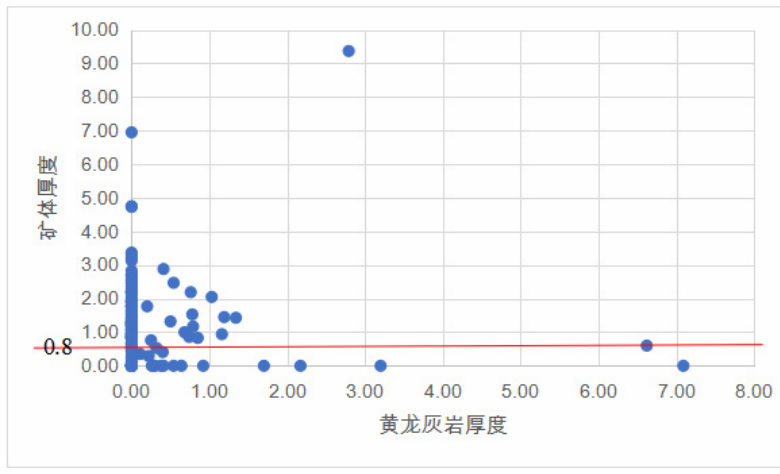

图6 黄龙组灰岩厚度与矿体厚度关系图

3. 3矿石质量受硅和铁影响变化规律

通过对研究区 2220 个化学基本分析数据处理, 作为铝土 矿选冶有害物质的硅和铁, 对铝土矿物 (主要为一水硬铝石) 富集有直接影响作用, 即随着硅铁不断流失减少, 铝不断富 集成矿 (图7)。

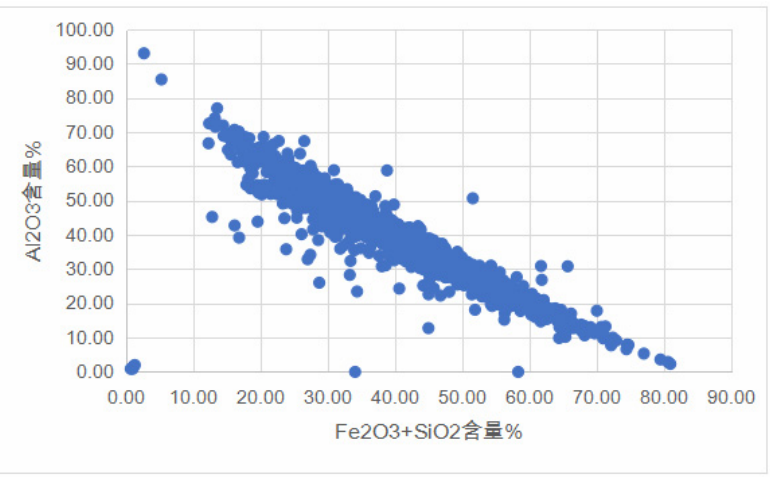

图7 铝与硅、铁变化关系图

\section{4 结束语}

加里东运动以后, 泥盆至石炭纪后期出现沉积间断 ${ }^{[1]}$,
下伏韩家店群页岩地层遭受到风化剥蚀, 大部分可溶元素随 着流水流失, 留下 $\mathrm{Al} 、 \mathrm{Fe} 、 \mathrm{Si}$ 等元素; 随着海平面上升, 研究 区在石炭纪后期海水逐渐侵入, 接受短暂沉积, 形成黄龙组 灰岩; 经过海水搬运和分异沉积, Si、Fe逐渐流失, Al进一步 富集 ${ }^{[2]}$; 二叠纪早期至梁山期, 研究区处于泄湖到半沼泽相 环境, 在水体平静的凹地中, $\mathrm{PH}$ 值相对较大, 为弱氧一还原环 境, 往往有黄铁矿等沉积, 在水体浅而动荡的环境中, 往往有 铝土矿沉积, 在梁山后期沼泽化环境中, 往往有炭质页岩沉 积; 在铝土矿形成后, 随着后期地壳抬升和断裂活动, 海平面 下降, 形成旦坪向斜, 该褶皱构造南东翼较宽缓, 而北西翼较 陡窄, 海水退去, 在靠近海侵海退的盆地一侧, 经受更多搬运 和分异沉积, 故旦坪向斜南东翼铝土矿质量相对较好, 厚度 也较北西翼大; 最后经历多次淋滤作用, 使铝土矿进一步去 硅去铁, 形成优质铝土矿, 尤其在褶皱末端和转折处这种半 封闭环境下 ${ }^{[3]}, \mathrm{Al}$ 得到更好的富集和保存; 在旦坪向斜构造 基础上, 二叠系、三叠系完整沉积地层, 作为铝土矿盖层, 提 供了很好的保存环境, 以至形成如今发现的多个大中型铝土 矿床。

\section{[参考文献]}

[1]刘幼平,程国繁,崔滔,等.贵州铝土矿成矿规律 [M]. 北 京:冶金工业出版社,2015,21(6):110-115.

[2]李艳桃, 肖加飞,付绍洪, 等.贵州主要铝土矿矿集区成 矿特征对比研究 [J].地质找矿论丛,2014,29(4):415-416.

[3]杜远生,周琦,金中国,等.黔北务正道地区早二叠世铝 土矿成矿模式[J].古地理学报,2014,16(1):4-5.

\section{作者简介：}

杨仕江(1984--), 男,贵州开阳人, 汉族, 本科学历, 中级工 程师,从事工作：资源勘查工程专业工作。 